\title{
MESA DE CONVERSACIÓN NUEVAS VOCES, NUEVOS ENFOQUES Y NUEVOS TEMAS EN LA DISCUSIÓN FEMINISTA
}




\title{
MESA DE CONVERSACIÓN \\ NUEVAS VOCES, NUEVOS ENFOQUES Y NUEVOS TEMAS EN LA DISCUSIÓN FEMINISTA
}

\begin{abstract}
Por Alejandra Araya Espinoza
Historiadora, académica de la Facultad de Filosofía y Humanidades y directora del Archivo Central Andrés Bello de la Vicerrectoría de Extensión y Comunicaciones de la Universidad de Chile
\end{abstract}

\begin{abstract}
Alejandra Araya: bueno, primero que todo, me gustaría agradecerles el tiempo, el interés. Me siento muy honrada de conversar con ustedes en mi doble calidad de historiadora y también de feminista, así que me parece muy importante este diálogo, que creo que será una conversación larga. Esta actividad está en el marco de la Revista Anales de la Universidad de Chile, una de las revistas más antiguas del cono sur. En esta etapa de la revista la idea es generar volúmenes que den cuenta, como ha dicho Faride Zeran, directora de la revista, de la contingencia y de la atingencia, en una publicación que queda, que es una especie de monumento de lo que pasa en el país. Esta es la primera vez que se va a dedicar al tema del feminismo, género y las mujeres en toda su larga historia, por lo que es muy importante como hito y tiene que ver con una fórmula que ha adoptado el equipo editorial, de generar estas mesas de conversación un poco más sueltas que los textos de Anales propiamente tales, que son más ensayísticos. El número también va acompañado de un dossier histórico. En ese marco está lo que vamos a conversar.

Camila Vallejo es feminista, geógrafa de la Universidad de Chile y diputada del Partido Comunista del distrito 12, una figura pública muy conocida en este momento, quien además fue presidenta de la FECH entre el 2011 y el 2012. También estamos con Araceli Farías, estudiante de Música de la Pontificia Universidad Católica de Chile de cuarto año, vicepresidenta de la Federación de Estudiantes de la Universidad Católica (FEUC) por la Nueva Acción Universitaria, vocera de la Confederación de Estudiantes de Chile, feminista y militante de RD.

También damos la bienvenida a Emilia Schneider, estudiante de Derecho de la Universidad de Chile, feminista, transgénero y militante de la Izquierda Autónoma, ex vocera de la Coordinadora 8 de Marzo y vocera de la ex toma de
\end{abstract}


la Facultad de Derecho. Agradecemos también la presencia de Claudia Apablaza, escritora, psicóloga, feminista y máster en Teoría Literaria, editora de Los Libros de la Mujer Rota y con trabajo desarrollado en LOM y en Cuarto Propio. Además, ha ganado distintos concursos literarios y el Premio Alba.

Yo soy Alejandra Araya, historiadora. Vamos a empezar con una pregunta general, que tienen cinco minutos para responder. Camila tiene más experiencia porque en el Congreso tiene que hablar corto y preciso los cinco minutos. Las primeras llamadas olas feministas de este 2018 se están entendiendo como un fenómeno nacional, con distintas implicancias, distintos niveles. ¿Cómo han vivido este momento específico desde sus áreas de desempeño?

Claudia Apablaza: yo más o menos hablo del área de la literatura, porque si bien soy psicóloga, la verdad nunca ejercí; me titulé para tener un título. Entonces, desde la literatura, desde el ámbito de la edición y escritura se ha vivido como un cambio radical. Yo les comentaba que hace diez años yo era casi la única feminista del mundo literario y en ese entonces el feminismo era muy mal mirado en literatura.

\section{Alejandra Araya: o sea, ¿decirse feminista?}

Claudia Apablaza: decirse feminista, decir que uno tenía una postura ideológica además de estética. Podría decir que incluso hace cinco años era un campo súper masculinizado. Desde ese campo masculinizado, lo ideológico no era tema porque para muchos la literatura no es ideología, o sea, la literatura es algo estético, es algo bello y es algo que hay que tener en un altar. Creo que el cambio fue brutal, yo ni siquiera me puedo todavía reponer, porque si bien soy feminista, siento que el cambio me trasciende mucho, va mucho más allá de uno. También es cierto que a veces, en estos movimientos sociales y culturales, uno no está a la altura del cambio, eso me pasa mucho: si bien me siento una mujer feminista, creo que las nuevas escritoras feministas me sobrepasan lejos.

Hoy hay muchas más mujeres publicando; hace cinco años, de diez escritores, publicaban a una mujer, yo creo. Actualmente, los editores están buscando escritoras, ya no están buscando escritores, la prensa está buscando escritoras. Yo tengo una pequeña editorial que se llama Los Libros de la Mujer Rota y cuando sacamos a un escritor hombre a la prensa no le interesa, les mandamos comunicado de prensa y no saben de dónde tomarlo, a no ser que sea un escritor gay y que tenga un discurso de nuevas masculinidades, ahí podría entrar a nivel de discusión de la prensa.

También se ha dejado ver a nivel de difusión, a nivel de lectores y lectoras. Creo que los lectores están buscando nuevas voces, leer a mujeres, encontrar un camino dentro de todo este movimiento feminista. Uno, desde la lectura, también 
puede apoyar niveles de pensamiento o vías de acción. Entonces yo hice una lista de escritoras, que no las voy a nombrar todas, pero también es muy importante que hoy hay diversidad de escrituras. Antes había un tipo de literatura que era mega literaria o una escritora súper racional, y hoy las escritoras tienen la libertad de escribir como quieran escribir. Antes había que escribir como escribían los hombres.

Emilia Schneider: bueno, a mí en lo personal me tocó vivir bastante de cerca este último auge del movimiento feminista. A mí me tocó ser vocera de la Coordinadora 8 de Marzo a principios de este año de cara a la marcha, siendo una convocatoria bien rupturista para lo que se venía haciendo. Viví bien de cerca ese proceso en que se amplía ese horizonte del movimiento feminista, que fue de condenar la violencia de género a un cuestionamiento más estructural de la sociedad cuando se transforma la consigna de "Ni una menos" a "Mujeres trabajadoras por la precarización de la vida". Yo creo que mi experiencia en el movimiento feminista, y lo que viene siendo la construcción de hace varios años de esto que se ha desencadenado, que parece haber empezado hace tres meses, pero en realidad viene construyéndose hace mucho tiempo, tiene que ver con la experiencia de ser estudiante. Ser estudiante y ser parte de las organizaciones estudiantiles en distintos espacios (en algún momento a las feministas nos tenían en espacios paralelos), en comisiones, como si la temática del género, la mal llamada temática del género, fuera una particularidad y algo sectorial.

Fue bien curioso vivir todo este proceso en que la política feminista en un momento corría por un carril separado al de la política del movimiento estudiantil, hasta que hoy ya se toma la agenda política del país desde el movimiento estudiantil. Es bien interesante. A mí me tocó ser parte de la Secretaría de Género de la FECH durante los años en que se trabajó el protocolo para denunciar el acoso que se aprueba a fines del 2016 y 2017 y el proceso del decreto Mara Rita, el reglamento en torno al uso y el reconocimiento del nombre social de las y los estudiantes trans, en particular desde mi experiencia personal de ser una estudiante trans de la Universidad de Chile. Es bien interesante mirar todo eso en retrospectiva, ver cómo hace mucho tiempo compañeras que nos hemos encontrado en estos espacios fuimos construyendo también una mayor politización del feminismo.

Ser estudiante de Derecho es bien curioso, es una rama del conocimiento muy masculinizada en que estas perspectivas se han abierto un espacio, lo que también ha sido un costo del trabajo de muchas académicas, de muchas estudiantes. Yo soy ayudante de la cátedra de Género y Derecho con la Profesora María Angélica Figueroa, que hasta el momento es un electivo, no un ramo obligatorio ni tampoco una perspectiva transversal a toda la formación. Creo que eso es lo que resume mi vivencia, creo que entré a la universidad y a la organización estudiantil en un 
momento en que el feminismo aún era una perspectiva muy accesoria, muy sectorial. Y vivimos desde el 2015 o tal vez un poco antes, la necesidad de las Secretarías de Género, de combatir la violencia de género en la Universidad, la discriminación, hasta llegar a ver esto desde un prisma transversal para analizar la totalidad de la política.

Camila Vallejo: yo tengo varias miradas respecto a esta ola feminista, como se la llamó. Yo no sé si era una ola, pero a mí me sorprendió muy positivamente. Porque una parte del análisis la hago de la retrospectiva de mi experiencia de vida y cómo empiezo a hacer una relectura de mi pasado por la FECH, de dirigente estudiantil, de mi experiencia en el colegio, de la universidad, del entorno y todas las formas de violencia que uno vivió y no se dio cuenta. Pero también desde el Congreso: cómo impactó este debate nacional dentro de las paredes del Congreso nacional, dentro del trabajo distrital, porque no es lo mismo y no impacta de la misma forma, y a nivel de partido, también. Porque yo recuerdo que para mí, por ejemplo, en la dirigencia estudiantil este tema en el entorno no era un tema central, para nada, no había solidaridad de género.

Alejandra Araya: y estamos hablando de tiempo reciente, de ayer.

Camila Vallejo: en el mundo de las compañeras de izquierda, en general, primaba más que nada la competencia por la militancia con el otro, pero no había acompañamiento. El tema sobre violencia sexual, el abuso, estaba muy relegado, no estaba visibilizado y lo único que tratábamos de instalar eran básicamente las distintas formas de opresión que tenía la mujer en el ámbito educacional, pensión, salud, trabajo, pero no había un énfasis de esto que detonó finalmente en la ola feminista por las redes sociales y que empezó porque muchas mujeres conocidas del ámbito del cine, mujeres famosas, empezaron a denunciar temas de acoso. Pero en ese entonces era como tímido, uno lo planteaba y al tiro el resto decía "ah, el tema de las mujeres", y quizás se hacía más fuerte los 8 de marzo, ahí podíamos sacar un poco más de, no sé si valentía, pero un lugar más seguro para hablar de los temas de violencia. Claro que ha cambiado. O sea, el debate en el mundo de la izquierda, en el mundo estudiantil, ha cambiado mucho a partir de los últimos años en relación a lo que era recién el 2011, y a pesar de que había programaciones feministas y de que se estaba trabajando en esto, no era un tema transversal y no tenía la fuerza que hoy tiene.

Alejandra Araya: aunque muchos mencionan que el 2011 es un hito de clivaje con el actual movimiento. 
Camila Vallejo: sí, el 2011 trató de que no nos quedáramos en el cuestionamiento a la lógica de mercado en la educación para intentar cuestionar las bases de una sociedad de mercado, el lucro como ente rector o eje rector de la salud, de las pensiones, de la vida en general, y ya ese ejercicio político de debate en el mundo estudiantil es un ejercicio que se empieza a mantener y fortalecer en nuevos aspectos. El movimiento feminista no se queda sólo en la violencia sexual, como decía la compañera acá, sino que cuestiona un sistema patriarcal, capitalista, y eso me parece que es algo que uno podría asimilar con el debate que se trató de hacer en el movimiento estudiantil. Pero esto es un paso evolutivo mayor, creo yo, y para las que en el Congreso hemos venido trabajando en proyectos de ley sobre la materia, fue una oportunidad maravillosa de poder avanzar más rápido.

Alejandra Araya: de hecho, ayer el senador Guido Girardi anunció que van a poner el tema de la ley de aborto.

Camila Vallejo: antes de estas movilizaciones, ir a una comisión donde hay puros hombres a plantear un tema sobre equidad de género, derechos de las mujeres trabajadoras, derechos sexuales reproductivos, era "qué lata", todos te miraban pésimo y tiraban la talla, lo tomaban con humor. Ahora no. Ahora todos tratan de sumarse, simpatizar con el discurso, hacen sus propios discursos y las cosas tienden a avanzar mucho más rápido. Aprovechamos la oportunidad para presentar la idea de la Comisión de Mujeres y Equidad de Género y logramos sacarla en un día. Imagínate que tenemos más de 50 proyectos de ley sobre la materia que estaban durmiendo hace años, no sólo los presentados por nosotros sino que eran de otras mujeres que ya no están en el Congreso, que venían solitariamente presentando estos temas, como María Antonieta Saa o Denise Pascal; incluso ella, teniendo una mirada más conservadora, había planteado estas temáticas. Para nosotros ha sido una gran oportunidad de poner en el centro o de relevar a un grado mayor de importancia la agenda de género y todos los temas que tienen relación con el respeto de los derechos de las mujeres.

Alejandra Araya: vamos a volver con algunas cosas que has dicho, pero terminemos esta ronda con Araceli.

Araceli Farías: sí, fue quizás uno de los meses más agitados que he tenido en mi vida universitaria estudiantil y es algo que quizás muchas queríamos que llegara en algún momento. Superó todas las expectativas que podría tener y todo el alcance que podría haber alcanzado el movimiento feminista en Chile. Muchas han esbozado que incluso un par de meses antes era impensado tocar ciertos temas en 
ciertos espacios. En la UC en específico es muy difícil decir que una es abiertamente feminista, que está a favor de la interrupción voluntaria del embarazo en todas sus causales y cosas por el estilo, por un conservadurismo importante que no sólo está a nivel estudiantil. La UC tiene un gran porcentaje de sector conservador que no sólo no está a favor de estos principios sino que también es algo muy presente de la doctrina de la UC, de la identidad de la UC y en la misma sala de clases, donde los profesores lo plantean de forma explícita. Entonces, plantear temas como la necesidad de tener un protocolo que finalmente se llevó a cabo con ciertas falencias al inicio de su ejecución fue sumamente complejo. También plantearle ciertos temas a la universidad misma, al estudiantado.

Pero si bien este año el tema permeó todos los espacios y llegó también a reventar el movimiento estudiantil, de todas maneras es algo que quizás no pudimos tomar de la manera más adecuada, es algo que nos rebalsó como representantes. Porque también dentro del espacio mismo hubo un cuestionamiento muy potente hacia la representación institucional y hacia la forma en que se construía política en las universidades, en los espacios educativos. Entiendo también la masculinización de la política, donde hasta hace no mucho estaba muy marcada la idea de que a la compañera se le invisibilizaba en las asambleas, en los plenos, se le interrumpían las palabras por los mismos hombres, los compañeros repetían lo mismo que tu decías, pero finalmente era la idea que había propuesto el compañero. Cuando salían temas de género, por ejemplo, en prensa, como todos los voceros eran hombres, finalmente eran ellos los que salían respondiendo. Gracias al trabajo con otras compañeras salió, por ejemplo, la idea de convocar a una marcha para el 16 de mayo con la consigna de "educación no sexista". A pesar de que sabíamos que el problema estaba focalizado en los protocolos, en cómo se hacían cargo las instituciones de los casos de violencia sexual, era importante ir un poco más allá porque el problema no se iba a solucionar con medidas reactivas en torno a qué hacer cuando el hecho ya fue realizado sino que había que atacar las raíces de la educación, donde desde que somos niñas nos meten en la cabeza cómo debemos comportarnos y se naturaliza el comportamiento de nuestros compañeros, que en las universidades son los que nos pasan a llevar y nos violentan.

Ahí se planteó esto que no se había dado hace mucho tiempo, la idea de que las vocerías las ejercieran justamente las mujeres de las federaciones, y plantear que era una lucha que debiesen impulsar las mujeres y no los compañeros, entendiendo que no están excluidos de la movilización, pero no son ellos quienes deben llevar el liderazgo, no son quienes deben llevar adelante la movilización. También creo que muchas de las cosas que me pasaron a mí en particular y a las compañeras en el mismo espacio tuvieron que ver con enfrentar lo difícil de organizarnos en este nuevo escenario, que tenía por un lado a la CONFECH, a nuestras mismas compañeras de 
la Secretaría de Género organizadas en la FEUN, y a las organizaciones feministas. Estábamos todas luchando por lo mismo pero por carriles separados y fue muy difícil organizarnos por cosas que quizás tienen que ver con nuestra crianza, porque hasta hace no mucho, como dice Camila, la participación en política no estaba cargada de un sentimiento de solidaridad, había mucha competencia de quién era vocera, quién no, quién aparecía más, quién aparecía más en prensa. Pero hemos ido aprendiendo y entendiendo que somos una fuerza importante en la sociedad chilena, que se pueden impulsar cambios. También hemos visto que en un periodo corto de tiempo, si bien son temáticas que se vienen asentando hace mucho, el avance que se ha logrado en los últimos meses ha sido impresionante. En mi carrera, hace un año, si increpabas a un profesor y le decías que sus comentarios eran machistas o misóginos, se reían en tu cara y a veces también los mismos compañeros. Ahora son ellos mismos los que se reúnen en asambleas de hombres para hablar de la forma en que han hecho clases todo este tiempo, de la forma en que se han relacionado con nosotras y también solicitando ayuda para cambiar. También, por ejemplo, algunos amigos están eliminando grupos de WhatsApp en los que se juntan para hablar de pichangas y mandar fotos de minas; los están borrando porque hubo un cuestionamiento.

Alejandra Araya: ¿eso es práctica común? Porque yo hablo desde otra generación, analfabeta digital.

Araceli Farías: claro, desde muy chicos la mayoría tiene ese tipo de WhatsApp y entonces son quizás pequeños gestos que te van dando pequeñas luces de que se está sembrando mucho más profundo la semilla, para que en un futuro podamos llegar a cosas más grandes.

Alejandra Araya: me interesaría saber cómo llegan al feminismo. Todas se declaran feministas y eso me parece muy notable en retrospectiva o viendo los cambios generacionales. ¿Cómo hacen este diálogo? Emilia ha dicho muy enfáticamente que el feminismo vive una politización. Pero quizás para otras, unas feministas de los ' 80 , ‘90, sería como un contrasentido decir feminismo y no politización, quizás ahí hay una distancia o diferencia a la cual me gustaría que se refirieran. ¿Por qué se declaran feministas? ¿Cómo llegan a eso? ¿Qué distinción hacen entre feminismo y política?

Emilia Schneider: para una feminista de los ' 80 y otros procesos es muy raro hablar de que el movimiento feminista vive este proceso de politización. Yo creo que responde al desarrollo histórico del feminismo en Chile, que vive silencios. Este 
fue importante para la lucha contra la dictadura y yo lo veo como una herramienta política por la recuperación de la democracia. Entonces, posterior a ese momento, hay un silencio y un avance de políticas neoliberales, por ejemplo, de equidad de género, radicada en el SERNAM, y en lo que fue después el SERNAMEG, o también podríamos ver el ministerio de Desarrollo Social en la familia.

Por qué yo me declaro feminista. Creo que ahí hay que partir diciendo que el feminismo no es una ética individual ni un estándar con el que uno deba vivir la propia vida. Para mí es una herramienta política y quienes somos reconocidas y nos reconocemos como feministas tenemos que adoptar esa perspectiva analítica frente a todos los conflictos sociales a los que nos enfrentamos. No se trata de una ética individual que tenga una check list de cuán feminista soy. Yo creo que tiene que ver con eso y entender que hay distintos feminismos, también el feminismo está en disputa.

Alejandra Araya: pero tú, en lo particular, ¿cómo llegas al feminismo? ¿'Te conectas con grupos feministas? Porque hay lecturas específicas, experiencias personales.

Emilia Schneider: yo creo que nací feminista por necesidad, de alguna manera. Hablando desde mi experiencia personal, me tocó vivir en el colegio, por ejemplo, las movilizaciones del 2011 y de repente uno se encontraba en los espacios políticos más tradicionales, como decía Camila, en los que era muy difícil dar esa disputa. Eran muy pocas las que estaban en eso y cuando uno vive esos procesos de politización también te encuentras con esas perspectivas políticas, que de alguna manera te integran más y te responden más a esos procesos de transformación social que tú misma requieres por sentir la misma contradicción. Creo que por eso uno se vuelve feminista, por necesidad, de alguna manera. A mí me tocó hacerlo al alero del movimiento estudiantil, pero como te decía, por un carril separado, en el colegio, organizando cosas en torno al tema de la disidencia sexual.

Camila Vallejo: yo creo que uno se declara feminista pero es una aspiración permanente, es un proceso de aprendizaje permanente, de reflexión permanente. A pesar de declararme feminista, de repente me encuentro con que esta forma de pensar, esta práctica, es parte de un patrón muy masculinizado y muy machista.

El 2011, por ejemplo, yo hablaba de esto pero no pensaba en el feminismo como una corriente teórica política, decía desde la experiencia que eran importantes estos temas, pero no se hablaba de feminismo, no se escuchaba en mi entorno de feminismo como un movimiento político teórico. Entonces, lo que nosotros o yo hacía era plantearlo en cada uno de los discursos, en los discursos de asunción de la FECH. También tratarlo en el partido, porque esto es un problema central, no secundario, no es un problema que tendría que discutirse en la comisión de mujeres. 
Y ahora claramente uno refuerza más esa idea. Por ejemplo, dentro del partido, no disociar el marxismo con el feminismo porque es tan importante entender y combatir el capitalismo como el patriarcado, porque se alimentan mutuamente y probablemente el patriarcado persiste sin el capitalismo, pero el capitalismo necesita el sistema patriarcal. Eso es lo que ha ido definiéndome mucho más, yo creo, como una feminista marxista, y lo que nos ha permitido, junto con otras compañeras, asentarnos con mayor seguridad en la etiqueta de feminista, como una contribución política teórica en nuestras discusiones. Yo me declaré feminista hace pocos años, aunque venía siéndolo desde antes. Es como una declaración, es como mostrar: "aquí soy y vengo de esta vocería y de un posicionamiento político necesario", a pesar de que es un aprendizaje permanente.

Araceli Farías: últimamente nos han hecho harto esta pregunta y es muy difícil mirar hacia atrás y encontrar el momento exacto en el que esto te hizo sentido y te hizo sentir que todo lo que haga hoy, todas mis acciones, tienen que llevar eso como horizonte. Pero hay dos frases que pueden, si bien no es un momento específico, abarcar bien el cómo se llega a eso. Uno es que una, como mujer, en base a sus acciones y vivencias, es feminista siquiera antes de saberlo, quizás cuando te das cuenta en tu niñez de ciertos cuestionamientos que hiciste y no entendiste si había algo teórico. Eran cosas que tú netamente sentías. La segunda también es que te encuentras en el feminismo por necesidad y por todas las cosas que te toca vivir, que te toca enfrentar y que te violentan, que te hacen encontrar refugio en esta idea de que nosotros debiéramos luchar por el feminismo.

Creo que si bien es difícil marcar un momento de "este día me di cuenta de que era feminista o quería llegar a serlo", hay varios momentos claves, como mi paso por el colegio y la universidad. Yo iba a un colegio de monjas, de sólo mujeres, en que estaba muy marcada la idea de que la niñita tenía que ser criada para ser ama de casa, aprender a tejer; donde la aspiración máxima era casarse y dar la PSU era un tema casi tabú. También había un matonaje gigantesco hacia la diversidad sexual, es bastante duro que en mi colegio se haya dejado de amedrentar a mis compañeras por ser lesbianas sólo cuando salió la Ley Zamudio. Tenía que morir una persona para que te dejaran de citar a reuniones con las monjas o poner condicional por el simple hecho de que te gustaran las mujeres. Todo eso se fue aglutinando, para mí todo esto tiene una cuota importante de rabia que te hace enfrentarte a este modelo de sociedad. Pero donde vi el machismo de la forma más cruda quizás fue en la universidad desde que llegué a postular, porque estudio Música y uno podría pensar que el arte es medio hippie, que no hay tanta discriminación, que la gente se quiere, pero no es tan así. De hecho, para entrar a Música hay que dar una prueba especial de aptitudes y la PSU, y el día que fui a dar mi prueba especial de Música, 
en la mención a la que yo estaba postulando, que es composición, éramos como 30 personas y dos éramos mujeres. El primer comentario que nos hicieron en la sala de la entrevista fue "dos mujeres, qué valientes, qué hacen acá". Era súper duro, yo era pendeja, tenía 17 años y estaba postulando, y fue súper violento sentir que ya de frentón, sin haberte preguntado nada, eras menos capaz de hacer algo por ser mujer. Me tocó ver comportamientos muy machistas de mis profesores, las clases mayoritariamente son particulares, entonces había un trato cercano con los académicos y muchas veces se pasaron para la punta. Había muchos comentarios misóginos, muchas de las referencias y analogías para explicar cosas desde el punto de vista pedagógico eran utilizando ejemplos sexuales muy crudos.

Alejandra Araya: en una universidad católica, eso es una tensión.

Araceli Farías: claro, y además una universidad que ha sido una piedra de tope en toda nuestra historia por la lucha de nuestros derechos reproductivos: pienso en las intervenciones de Ignacio Sánchez en el tema de las tres causales, su incidencia en el Tribunal Constitucional, que sabemos que es un actor importante para que se obtuviera la objeción de conciencia institucional. Todo eso fue tensionándome internamente y al final llegué hacia el camino de ser feminista por una cosa quizás reaccionaria, por ver cómo una institución, a través de múltiples ámbitos, pisoteaba la dignidad de la mujer de forma cotidiana y constante. Ahí me fui encontrando con compañeras que estaban en la misma que yo en distintas facultades y desde ahí el rechazo hacia la violencia sexual. Llegué a participar a la Secretaría de Género y me fui interiorizando más, y pude comprender que era algo que permeaba en todos los ámbitos de la vida política, de la participación y de la universidad, y desde donde pude entender que era algo que tenía que ser llevado adelante por nosotras, sin distinguir el tipo de espacio. Así es más o menos la historia que yo trato de hilar de cómo esto se fue asentando y sentando bases y profundizándose en mí misma.

Claudia Apablaza: ha sido un proceso largo llegar a decirme a mí misma feminista, porque de cierta medida siempre lo fui, de base, desde niña todas mis lecturas eran de mujeres, no me gustaba leer a hombres, no me hacían sentido. Entonces trataba de no leer mucho a escritores chilenos porque en ese momento el mundo estaba poblado por escritores hombres. Me fui más por escritoras extranjeras como Simone de Beauvoir, Virginia Wolf, Marguerite Duras; todas mis lecturas, y desde la inocencia porque tenía 15 años, eran de mujeres, y me sentía súper identificada con Simone de Beauvoir si bien también desde la diferencia, porque ella es una mujer europea y obviamente yo soy latinoamericana, chilena, entonces sentía mucho esa tensión, esa diferencia. Pero esa ya era otro tipo de diferencia, no de feminismo 
sino que de clase, de privilegios. Después me di cuenta de que me gustaba más leer mujeres, buscaba más autoras mujeres en Latinoamérica como Rosario Castellanos, Elena Garro o Hilda Mundy. Siempre estaba buscando esas referencias, pero eso era desde el nivel más de la inocencia. Cuando entré a estudiar a la universidad, yo estudié Psicología y después Literatura, también los textos que nos daban eran de hombres: Freud, psicólogos, psiquiatras y todos los profesores eran hombres; tampoco me sentía identificada ni con sus pensamientos, ni formas de mirar en ese momento la disciplina que estábamos estudiando, que era la mente. Entonces sentía la tensión de la diferencia, sentía la inquietud, el malestar, quizás, de que no está dentro de los planes de los académicos presentar otras lecturas. Ahí empecé a buscar por mi cuenta. Terminé Psicología, la dejé como disciplina y me metí a Literatura, pero fue lo mismo. El mundo está poblado de escritores, poblado de hombres, y uno iba haciendo una educación alternativa. Cuando empecé a publicar me tildaron de feminista, como que ahí me dijeron los medios, la prensa, no sé, "la escritora feminista”. Ahí dije: "bueno, sí, parece que lo soy".

Camila Vallejo: saliste del closet.

Claudia Apablaza: sí, me sacaron del closet. Me lo tenían que decir y desde ese momento, creo que fue el 2011, cuando me lo dijo una periodista que lo puso como titular, me hice cargo de ese titular. Me hizo sentido y empecé a mirarme en retrospectiva y a mis proyectos a futuro y sí, tenía esa línea de trabajo, de pensamiento. Después fundé una editorial que se llama Los Libros de la Mujer Rota, que está basado en Simone de Beauvoir, y la mayoría de las autoras que he publicado son mujeres. Siempre lo veo más desde la acción y después me doy cuenta en la reflexión que sí lo soy. Aunque puede sonar mal, me marcó el que mi colegio fuera súper exitista, conservador y quería que todos fuéramos a la universidad. La diferencia que comentaba Araceli no la vi, porque en el colegio en que estuve, el Instituto Inglés de Rancagua, cuico, conservador, Opus Dei, nosotros teníamos que ir a la universidad, nos metieron desde niños que nuestra función era titularse en la Chile o en la PUC. También viví una vida de privilegios. Mi madre salía a trabajar todos los días, mis padres son profesionales y eso también cimentó un campo. Nunca me vi como la mujer que se queda en la casa, la mujer que tiene que cocinar. Si bien mis padres no son abiertamente feministas, el entorno en el que viví daba la posibilidad para que las mujeres fueran tan importantes como los hombres dentro de la sociedad.

Alejandra Araya: ¿cuáles creen que son las condiciones que han permitido que masivamente se vuelva a hablar de feminismo? Porque todas han hablado de silencio 
o salir del closet, como que ha habido un gran hiato, pero han estado sucediendo cosas para que hoy día se hable masivamente del feminismo y se pierda el miedo de decirse feminista. ¿Qué pueden decir, desde sus experiencias y lugares, que ha cambiado?

Camila Vallejo: yo creo que muchas no nos atrevimos a catalogarnos de feministas porque no estábamos seguras de si realmente lo que tú vivías, lo que pensabas, se conjugaba en una corriente teórica que te permitiera decirte feminista. Entonces, yo creo que es parte de una toma de conciencia: una cosa es vivir las violencias de distinto tipo, cuando chica, en el colegio, la universidad, en tu militancia, en el espacio público, el trabajo; y otra cosa es tomar conciencia de que hay un sistema de opresión permanente que tiene un objetivo, sentido y causa. Empezar a tomar conciencia de que es un sistema de violencia. Ahí uno empieza recién a decir "entiendo esto, creo que no me gusta y quiero combatirlo". Creo que en general ayuda mucho el proceso de conciencia colectiva también, porque uno puede basarse en la experiencia personal, pero cuando te das cuenta de que tus compañeras, amigas, tu mamá, tu hermana, todas las mujeres que conoces de tu entorno cercano y de la periferia han vivido una experiencia similar, ayuda a decir que esto es un problema sistémico y estructural.

A mí me pasaba con las conversaciones de amigas, en fiestas, carretes, donde empezábamos hablar de esto todo el tiempo. Y es que estas cosas pasan todo el tiempo: las situaciones en la calle, con el amigo, con el tío; en las asambleas nos pasa así y cuántas veces no nos dimos cuenta de que no nos escuchaban, que era como un patrón de comportamiento. Creo que la experiencia personal y la conciencia colectiva ayudan mucho a que hoy sea abiertamente conocido. En todos los discursos durante el año, con excepción de los 8 de marzo, que era la temática principal, uno trataba de poner un parrafito de su discurso en esta materia, tímidamente, porque si te extendías mucho era incómodo y para uno también era incómodo. Pero cuando uno empieza a ver que hay muchas más mujeres, hay valentía y empoderamiento. Creo que uno de los factores tiene que ver con la toma de conciencia de la experiencia personal, sobre todo en retrospectiva, pero también con que no estás sola, eso ayuda muchísimo a que más mujeres se digan feministas. Tenemos en el Congreso a mujeres que dicen "yo no soy feminista, pero quiero la igualdad entre hombres y mujeres"; ellas no han hecho el proceso de toma de conciencia de que es básicamente esa la lucha que tiene el movimiento feminista.

Alejandra Araya: o como tú dices, la etiqueta tiene una cierta resistencia.

Camila Vallejo: claro, que somos unas hembristas y queremos dar vuelta la tortilla y construir un sistema machista al revés, que el matriarcado o el sistema feminista 
va a poner a los hombres en una situación de opresión; pero esas etiquetas, con este mismo movimiento, en la gran mayoría, se van revirtiendo. En algunos casos yo diría que ha generado reacciones totalmente contrarias y eso también es una preocupación que tiene que ser feminista, de cómo atacarlo.

Yo creo que tenemos mayor conexión y que las redes ayudan mucho, tal como pasó en el 2011, que las redes hacen que esto se expanda al otro lado del mundo y al otro lado del mundo está pasando lo mismo. Ya no es sólo que no estás sola, entre las amigas y tampoco con todas las mujeres de tu país, sino que ves lo que está pasando en Argentina, en Europa, que pasa en países incluso con otras culturas, países alejados no occidentales, y eso ayuda a que tú tomes cartas en el asunto y trates de posicionarte. Porque dices "si somos muchas mujeres, ¿por qué yo hoy sí he vivido estas situaciones?". Creo que es lo clave, lo que ayudó a que fácilmente otras mujeres que jamás pensaron en esto hoy se declaren feministas. Algunos les dicen que es por moda. Me da lo mismo que sea por moda o no, pero el catalogarte como feminista te obliga a hacerte cargo, revisar tu entorno y tomar posición y propuesta para ver cómo revertir esa situación.

Emilia Schneider: me sumo a las palabras que decían las chiquillas de la toma de conciencia y también de lo que hablábamos antes, de cómo se fue cimentando un proceso en que, por ejemplo, la temática principal que venía trabajando el feminismo fue la violencia de género. Se fue politizando, se fue dejando de entender como un hecho aislado que le pasa a mi amiga, me pasa a mí, sino que es una cuestión estructural. Sumado a eso, yo creo que hay un tema que tiene que ver con el proceso histórico político más amplio que se produce en Chile en los últimos 30 años. Yo creo que ahí hay algo muy decidor de dónde se producen estos estallidos feministas y cómo después del 8 de marzo de este año se instala de buena manera la consigna de que las feministas estamos contra la precarización de la vida. Ahí se relaciona mucho con el proceso de modernización que se vive en Chile después de la vuelta a la democracia.

Muchas personas, teóricos, personalidades del mundo académico e intelectual han planteado que este surgimiento, auge feminista, sería una suerte de movimiento meramente cultural por derechos individuales, contra estas manifestaciones más brutales de la violencia. Sería como una externalidad positiva en este proceso de modernización, produciéndose un choque del nuevo Chile y estructuras machistas y conservadoras que todavía persisten en la sociedad. Lo que omite ese análisis es que es sumamente tendencioso y que ha sido usado por el gobierno y tantas personalidades de lo que fue la Concertación. Yo creo que tiene que ver con que fue una modernización neoliberal que implicó la modernización de derechos sociales durante la dictadura y la vuelta de la democracia, la eliminación de todo 
atisbo de derechos sexuales y reproductivos. En el fondo, un avance de la misma precarización de la vida. Por eso no es casual que se produzcan estos estallidos en el mundo estudiantil, la lucha de No + AFP, la lucha de la seguridad social. Tiene que ver con una contradicción, un malestar contra las promesas de integración social, con la vuelta a la democracia, donde tuvimos un régimen progresista neoliberal que dio espacio a las mujeres dentro de ciertos márgenes. Avanzamos en inclusión en el derecho laboral, derechos políticos, pero eso no significó emancipación, no significó mayor libertad, ni mayor desarrollo pleno, ni más posibilidades de tener derechos sino que, por el contrario, significó más explotación, que el feminismo fuera relegado a un departamento de mujeres como fue el SERNAM, extrayendo esta perspectiva de todos los otros conflictos de la sociedad, todas las áreas importantes de la sociedad. Eso se omite, que esa misma modernización neoliberal fue la que profundizó las desigualdades en este país y las desigualdades sexuales sociales, digamos, y reproduciendo asimismo la división sexual social del trabajo y la doble explotación de las mujeres, porque con todo este proceso de supuesta democratización, supuesta modernización, donde las mujeres supuestamente ganaban en derechos, la explotación del trabajo reproductivo seguía estando ahí.

¿Por qué este año tomó tanta fuerza en el mundo estudiantil? Porque ahí tenemos en las carreras, en el sistema educacional, que se reproduce justamente este rol social, esta conducta, la división sexual del trabajo que se proyecta a lo universitario en el mundo laboral. Creo que eso es lo que viene, ese es el potencial de cambio que creo que tiene este movimiento feminista, que es negado muchas veces por interpretaciones que dicen que esto es un cambio cultural dentro de la línea de modernización que vivió nuestro país en los últimos 30 años. Yo creo que todo lo contrario: viene a irrumpir y a poner en cuestión las desigualdades sociales que se han asentado en esta naturalización de la división social sexual del trabajo, el rol de la mujer en la sociedad.

Alejandra Araya: o sea, en cierta forma tú dices que este feminismo le está dando el golpe final a la transición, ¿̇o no?

Emilia Schneider: yo creo que es condición de posibilidades, porque como todo en la historia, está en disputa. No es casual que el 8 de marzo fuera contra la precarización de la vida, que en el mundo de la lucha contra las AFP haya habido un encuentro entre mujeres y pensiones, que en la lucha estudiantil lo que se critique sea el legado de la transición, que a causa de la crítica a la mercantilización estén surgiendo estos focos de organización que son de avanzada y que complejizan incluso los proyectos que venían levantando los movimientos sociales. La educación pública no es solamente una educación como se planteaba en el 2011, pública, 
gratuita y de calidad. Con el concepto de educación pública podemos ahora hablar de cosas más profundas, lo que tiene que ver con esas luchas también, luchar contra este mercado profundamente sexista. Yo creo que eso es el proceso más macro, y también que dejemos nuestra posición de víctima, el típico encasillamiento de la mujer, de madre emprendedora, para ser un actor político. Esas son cuestiones que a mi juicio instalan al movimiento feminista hoy como una posibilidad de ampliación democrática en Chile.

Claudia Apablaza: estaba pensando en las condiciones. La verdad es que desde la literatura no lo podría decir porque en la literatura está este antes y después. Es una especie de nebulosa y no sé por qué se volvió tan radical el movimiento, quizás se internalizó desde un movimiento feminista global, cultural, y desde ahí las escritoras chilenas dijeron "ya, esta es la mía y voy a armarme de valor y voy a sacar todo lo que tengo dentro”. Pero no sé realmente qué pasó ahí en lo literario, porque antes el mundo estaba tomado por hombres o por mujeres muy masculinizadas, obviamente que sin saberlo y por necesidad. Prevalecían discursos literarios que no tenían el género como tema importante; al revés, había que masculinizarse. Yo me acuerdo que hace diez años, cuando empecé a publicar, tenía que masculinizar mis discursos frente a los hombres para poder estar en una mesa de escritores hombres y tenía que saber citar a demasiados autores hombres y todos los europeos y saber de todos. Y de repente eso cambió y lo hizo gracias a este movimiento, que no es un movimiento literario sino que social y cultural, que cruza todas las disciplinas.

Creo que en ese sentido, Internet, como decía Camila, es súper importante, porque mi discurso es tan válido como el de una gringa o el discurso de una mujer que vive en Japón. Nos pudimos conectar aunque estamos tan lejos, nos podemos conectar con otras mujeres que están muy distantes en términos reales. Entonces Internet ha sido clave. Para muchos, Internet es un demonio, pero para mí es una herramienta súper útil si la sabes utilizar bien y creo que este movimiento no sería tan fuerte si no existiera Internet. Otra cosa es que se perdió el miedo y el pudor de decir "me pasó esto y me pasó esto en este momento". Estamos tan acompañadas, somos muchas y a todas nos ha pasado algo, ¿no es cierto? Entonces ese miedo se ha ido perdiendo con el tiempo, se han creado las condiciones para que se pierda, porque antes esas condiciones no existían. Uno podría perder el miedo, pero a una la marginaban si es que hablaba un poco. Bueno, como decían en la mesa también, creo que el hecho de que el feminismo esté de moda nos ha ayudado. Aunque sea algo medio negativo y que no esté dentro de los parámetros ideológicos o racionales, creo que el hecho de que figuras claves, mujeres claves que son consideradas, como actrices o directoras de cine, hayan hablado, fue importante. Antes esas mujeres no 
hablaban, antes era como un tema de gente más desconocida o que a las raras les pasan estas cosas.

Araceli Farías: sí, son muchas cosas que permitieron llegar a este momento y no es casual y tampoco es algo que haya sucedido sólo este año. Llegó la transición y la democratización nunca llegó para las mujeres, porque seguíamos castigadas en muchos aspectos de la vida, que son los temas que se trataron de ahondar y tocar en la marcha del 8 de marzo de este año. Si bien hubo un largo periodo de silencio, donde quizás no había tanto ruido, sí estaban pasando cosas: el trabajo de hormigas, trabajo silencioso de muchas mujeres, y sí hubo ciertos hitos que marcaron precedentes para que a largo plazo se fuera acumulando un sentimiento de salir a disputar. Por ejemplo, creo que el primer gobierno de Bachelet fue algo sin duda muy importante en el país; tener un referente, una mujer en el puesto más alto del país es un precedente para cualquier mujer; independiente de si era de izquierda o de derecha, era una mujer que nos estaba representando a todos. En un sistema en que vemos que tenemos pocas referencias en literatura, deporte, en los montones de aspectos de nuestra vida e incluso de la historia, tener a alguien ahí, haciendo historia, fue también algo importante para que se atrevieran más las mujeres a disputar el poder político, que es un aspecto que sigue en deuda. Hemos avanzado en el último tiempo, pero quizás más bien centrados en los espacios educativos: las primeras Secretarías de Género fueron apareciendo el 2010; yo entré a la universidad el 2014 y me enteré de que esto venía pasando hace no tanto atrás, porque en la UC se crearon en el 2016. Luego se fue problematizando un poco más, pero es algo que ya se venía planteando en los distintos espacios desde antes y que se fue agudizando en los casos de denuncias contra profesores o contra compañeros en muchas universidades que fueron bastante emblemáticas y que ejercieron presión para hablar del tema. Son denuncias que se hicieron públicas y ponían en jaque y obligaban a ciertas personas a referirse a estos temas, y a las instituciones, a hacerse cargo.

Más allá de cómo lo hayan hecho en la práctica, creo que fue bastante importante cuando comenzaron a hacerse públicas ciertas denuncias, cuando ciertas mujeres quisieron ser pioneras en esto, arriesgarse, poner su cara en lo público para finalmente dar un impulso a más personas. Esto también relacionado con Internet, con la globalización y las redes sociales, todo ha ayudado mucho a ver que son procesos que no sólo se están dando en Chile, cosas que actrices de Hollywood están denunciando, campañas como el "Me too". O que el discurso de muchas premiaciones haya estado enfocado en el rol de la mujer en el cine, en la violencia que viven las mujeres en ciertos espacios más relacionados con la cultura pop; todo ha ido visibilizando también esta temática y haciendo que se reconozca en 
personas que quizás no están metidas en la discusión más académica y elitista en la universidad. Sabemos que somos personas privilegiadas por tener acceso a ese nivel de discusión en nuestros espacios, pero acciones así pueden llegar a la dueña de casa que está viendo el matinal y vio la premiación del día anterior en Estados Unidos. Es un mensaje que le puede llegar más fácilmente en lo que sería el resto de sus quehaceres diarios.

Y este año en particular, si bien el tema de los protocolos es uno que se viene tocando hace mucho tiempo, que se ha peleado incansablemente tal vez desde un nicho más personalizado en mujeres que algo más empatizado por todas las comunidades universitarias, yo creo que este año algo que hizo que se acumulara mucha rabia y que hizo reventar todo esto fue el caso de "la manada" en España, porque por la misma fecha, en el sur, en la Universidad Austral, deciden tomarse la universidad. Ahí empiezan a brotar las tomas feministas en distintos planteles educativos, lo que alcanzó un revuelo increíble y sentó las bases para que se pudieran paralizar los espacios, para que las comunidades educativas pudieran hablar del tema. También fue un llamado a las mismas estudiantes a tomar responsabilidad y que se pudieran llevar a cabo estas discusiones con nuestros profesores, funcionarios, compañeros y también en los espacios sociales con nuestra familia, amigos. Ese tipo de cosas hizo que esto tomara mucha más fuerza. También el hecho de que se partiera por la violencia sexual, ya que la violencia de género es más transversal, porque es muy complejo que alguien no esté de acuerdo con el rechazo de la violencia sexual. Hoy en día la persona que entra a cuestionar eso es profundamente castigada en el espacio público, contrario a lo que pasaba antes, y desde ese punto de partida profundizar en torno a feminismo y temáticas de género es mucho más fluido de lo que era hace un par de años. La discusión ha avanzado de una forma muy rápida en poco tiempo.

Camila Vallejo: yo creo que la historia reciente, de la transición, dictadura, postdictadura o transición ha tendido a profundizar y precarizar la vida de todos, particularmente la de las mujeres, que han salido al mercado laboral pero deben cumplir doble o triple jornada. Sin embargo, ese proceso tiene sus propias contradicciones y no es tan lineal. Por ejemplo, en cuestiones como el debate puesto sobre las tres casuales, que hoy se señala que no es suficiente pero que fue una lucha muy difícil para muchas mujeres. Ese debate logró visibilizar la otra parte, o sea, la reivindicación de las mujeres, pero por otro lado, una resistencia conservadora que a través de los medios e incluso de las redes sociales fue condenada públicamente porque se le puso cara. Esto existe en este país, no es algo que esté en la mente de las mujeres; está ahí y el discurso es tan brutal como lo trasmiten ciertos parlamentarios. Eso ayudó a generar un cierto grado de malestar ante un machismo que no existía 
simplemente en el discurso de las mujeres feministas sino que estaba materializado, tenía vida.

Alejandra Araya: que atraviesa el cuerpo por completo.

Camila Vallejo: claro, y lo otro que comparto es que el movimiento todavía tiene una deficiencia en los sectores de mujeres trabajadoras. O sea, las que viven la opresión por justamente trabajar y trabajar y no tener remuneración por eso. Ellas aún no están conscientes de que lo que hacen es un trabajo y ellas también deberían reivindicar el hecho de que son parte de la cadena productiva y que el capitalismo no las está considerando, las está explotando. Cuando uno va a hablar, muchas te dicen "no, es que yo estoy en la casa y no trabajo"; muchas otras no se declaran feministas pero dicen "es que yo preferí, opté, por quedarme en la casa porque me sale más barato que salir a trabajar y que me paguen un salario bajo, me ahorro todo lo que significa pagar el transporte de mi hijo y la colación”. El gasto en los costos del trabajo doméstico reproductivo ronda las 600 lucas, 500 lucas, y probablemente ella salga a trabajar y le paguen 300. Para qué, ese es el análisis que hacen. Ellas no se declaran feministas, ellas ven con distancia el feminismo porque todavía, a pesar de los avances en el discurso, está muy centrado en el tema de la violencia sexual, como un tema no político. Ese es un desafío muy grande del movimiento, que ha sido masivo pero que todavía no ha calado en una base importante de mujeres.

Alejandra Araya: hablemos de eso, entonces, de los desafíos de este movimiento que genera muchas expectativas, que genera también, como ustedes han dicho, muchas reacciones, tanto de oposición como de apoyo. Desafíos, como señala Camila, que quizás tienen que ver con esto, con que hay un proceso que recomponer en cuanto a la despolitización que produjo la dictadura y la transición a la democracia, cosa que uno puede ver en la palabra ideología. El miedo al feminismo es porque hoy se ve como una ideología y en tanto ideología, es peligroso. Y, por lo tanto, ahí también había un desafío en el terreno quizás de la política más clásica, del trabajo de base, de politización del discurso. ¿Cómo ven ustedes esa inflexión? Porque si volvemos a la metáfora de la ola, en la cresta de la ola pueden pasar dos cosas: se desmorona totalmente y se la traga la playa o se podría generar una especie de maremoto que pueda transformarlo todo. ¿Qué desafíos ven ustedes ahí desde sus ámbitos de acción sobre lo que hay que hacer para que esto no quede solamente en la retórica del cambio y efectivamente sea social?

Emilia Schneider: o sea... 
Camila Vallejo: es parte de la vida.

Emilia Schneider: de por qué estamos aquí.

Camila Vallejo: yo creo que el hecho de conversar esto en espacios donde no se conversaba ya es un ejercicio de pedagogía política permanente en todas las trincheras. En el Congreso, que tiene más visibilidad y probablemente más resistencia, menos que en otras partes, pero una resistencia dura igual, es importante que el feminismo sea una corriente teórica política y que no se quede sólo como un tema de mujeres. Es una batalla por la emancipación de nuestra sociedad, por terminar con distintas formas de opresión, porque nos interesa lo que pasa con las mujeres trabajadoras que están trabajando en las casas, por las formas de violencia. Parece que el discurso ayuda mucho y también la acción política en las bases sociales, o sea, salir del Congreso, que es un espacio de visibilización, y si podemos llegar a través de la prensa, de La Cuarta o Las Últimas Noticias, mejor aún, porque son los diarios que más lee la gente. Los matinales, todos los espacios de visibilización del debate, porque creo que el movimiento feminista tiene que ser capaz de tomarse todos esos espacios permanentemente, no sólo por la coyuntura de la ola feminista. Ojalá esto no sea sólo cíclico.

Creo que a muchas mujeres les han dicho toda la vida (y se han auto convencido de) que cumplen un rol secundario, que están ahí para obedecer, que su trabajo no es tan valioso, que por algo les pagan menos. En fin, yo encuentro que hay un tema casi emocional y es necesario hacerles ver que la mujer que está a cargo de la junta de vecinos trabaja fuera de la casa, que las mujeres que son dirigentes vecinales trabajan fuera de la casa, dentro de la casa, en la comunidad y además cuidan a los niños de las vecinas. Eso es un trabajo múltiple y sin él esta sociedad casi no se mantiene. Lo que no hace la salud, lo que no hace el sistema previsional, lo hacen ellas, si ellas no están, la pirámide se desmorona. Esa suerte de empoderamiento que implica no solamente sacar la voz por sacar la voz sino entenderte como pieza fundamental de un sistema político, económico, que sin ti se cae. Te empiezas a considerar a la hora de tomar decisiones y ese es el trabajo que tenemos que tener obviamente los parlamentarios y todas las organizaciones políticas y sociales, particularmente el movimiento feminista. Ese trabajo permanente en la base social es fundamental, sobre todo por la batalla ideológica. Los sectores conservadores nos ganan en las poblaciones y eso es una discusión que tenemos que tener. Yo soy de un distrito donde la mayoría de los alcaldes son hombres, de derecha y conservadores, progresistas en algunos ámbitos sociales, pero en estas materias son sumamente conservadores. Las políticas conservadoras que han impulsado en los municipios han traído una serie de consecuencias brutales en materia de embarazo 
adolescente y VIH, pues no han querido enfrentar esta realidad. Eso no lo estamos haciendo ver desde el mundo más progresista o desde el mundo feminista, de izquierda y feminista en particular.

Emilia Schneider: para mí, el desafío inmediato, sumado a lo que decía Camila, es seguir construyendo organizaciones donde no las hay. Ese es el potencial que muestra el feminismo hoy y que se muestra como una condición de posibilidad de volver a articular lo social, volver a articular las mayorías excluidas de las políticas como las mujeres, los sectores más precarizados no sólo en Chile sino que a lo largo del mundo. Los desafíos más inmediatos tienen que ver con, primero, superar los enclaves identitarios de la articulación del movimiento. ¿A qué me refiero con esto? Quizás es polémico lo que voy a decir, pero por lo menos desde el feminismo al que yo adscribo, desde mi organización, tiene que ver con descontinuar esta idea de que ser mujer es ser feminista. La articulación del feminismo va más allá de lo identitario y tiene que ver justamente con consensos políticos, con articulación de distintos sectores que buscan avanzar hacia una sociedad más democrática en sentidos amplios, una sociedad con derechos sociales y reproductivos, una sociedad donde el mercado y los intereses empresariales dejen de ser el eje rector de toda la vida y de cada uno de los aspectos de ella. Lo primero es eso, superar ese enclave identitario para entender que la articulación que requiere el movimiento feminista para avanzar hoy es bastante amplia. Como dice bell hooks, una feminista del feminismo negro, este es para todo el mundo y busca transformar a toda la sociedad, no solamente algo que se ha querido caricaturizar como problemas de mujer y de disidencia sexual. Entonces yo creo que primero eso, superar ese enclave y construir esta articulación amplia desde el feminismo como una cuestión que atraviesa todo el campo de lo social, de las y los subalternos, si es que se quiere decir así.

Un segundo desafío del feminismo, que es un desafío inmediato, es el no ser procesado en los distintos términos que te ponen los bloques políticos hegemónicos de los últimos 30 años. Este culturalismo de la derecha que te dice que esto es un cambio cultural con el que estamos todos de acuerdo, algo así como un llamado a los acuerdos nacionales. Yo creo que es una estrategia que tiene el gobierno de Sebastián Piñera de volver a la política de los consensos, que es lo que intenta hacer con la agenda mujer. Y por otro lado, no ser procesado en los márgenes sumamente limitados del progresismo neoliberal, que viene siendo rector de las políticas públicas en Chile durante los gobiernos de la Concertación y de la Nueva Mayoría. Digo que es un horizonte muy limitado porque se ha centrado en la focalización de recursos, entendiendo a la mujer en su rol social de madre, en tanto emprendedora, en tanto víctima, y no asumiendo el feminismo como una herramienta política. Creo que eso hay que superarlo de alguna manera para concebir al feminismo como una 
herramienta política para enfrentar la totalidad y hoy también como la condición de posibilidad de articulación de lo social y condición de posibilidad de superación del neoliberalismo.

O sea, puede que este feminismo reabra un proceso de reformas democráticas en Chile y conduzca a una ampliación de la democracia restringida en Chile. Yo creo que está ese desafío. Primero, asumir que no es mero cambio cultural, asumir la disputa del feminismo y construir un feminismo que impugne la política. Yo hablo desde mi organización, desde Izquierda Autónoma, donde hemos tratado de instalar que de alguna manera hoy el escenario es la disputa desde lo social contra este mercado sexista que rige y precariza los distintos aspectos de nuestras vidas. Refiriéndome a que el mercado educacional tiene un carácter profundamente sexista, donde se valorizan más social y económicamente ciertas carreras destinadas a la elite masculina versus las carreras más feminizadas, hay desafíos que quedan pendientes de este año, porque creo que hay saldos positivos tremendos, pero también una autocrítica. Este año no fue capaz el movimiento de auto representarse, de tener una sola voz y saltar a la disputa nacional con un Ministerio de Educación, con un gobierno que busca profundizar y mantener este mercado, este carácter conservador de la educación. Ese es el desafío, es hacer carne esta posibilidad que abre el feminismo de revitalizar los horizontes de la transformación política y social en nuestro país, hacer carne eso. Entender que el feminismo es disputa contra el mercado porque es disputa contra toda forma de dominación. Eso es lo que se juega en esta pasada, la disputa de los feminismos en juego es lo que nos abre esta posibilidad tan profunda de transformación que, creo yo, porta este movimiento.

\section{Alejandra Araya: ¿quieren agregar algo más?}

Araceli Farías: por un lado, desde el punto de vista de la militancia, un desafío es plantear estos temas y cuestionamientos a la interna de nuestras organizaciones y definir cómo desde la misma organización se plantean al país. Muchas críticas han surgido en torno a mi partido, que sugieren que se ha sumado al carro sin haber sentado las bases, sin tener una profundización basal importante dentro del movimiento. Son cosas relevantes, sobre todo cuando hay representación institucional de las fuerzas políticas en el Congreso, en distintos espacios donde se pueden plantear ciertos cambios institucionales que son importantes en torno a cosas como la tipificación del acoso. Cosas que tengan que ver con las pensiones, el sistema de salud, y que son importantes para las mujeres, que representan muchos aspectos de la precarización de la vida y que son importantes de atacar y que son el frente de muchas. Para nosotras, las estudiantes, es importante no quedarnos solamente en lo educativo, que sí, es uno de los problemas que quizás enfrentamos 
desde que somos más niñas y que puede tener repercusiones más profundas, porque es muy difícil sacarse todo eso de encima cuando toda la vida te han dicho algo.

Alejandra Araya: desde ahí la radicalidad de la demanda de la educación no sexista.

Araceli Farías: sí, claro, pero no es el único aspecto que hay que salir a disputar. Otro que es muy, muy importante es generar... no sé cómo decirlo en una forma que no sea paternalista, pero es muy importante recuperar la organización popular de mujeres. No sólo a través de organizaciones, sindicatos, juntas de vecinos, sino también involucrar a las mujeres migrantes, que es un tremendo tema, porque ellas se enfrentan aún a más prejuicios que nosotras por el hecho de no ser chilenas, no tener sus papeles en orden y todo lo que esto involucra. Yo trabajo de noche en un bar y la mayoría de mis compañeros son venezolanos, y las situaciones que veo que enfrentan cotidianamente mis compañeras venezolanas son terribles. Es importante llegar a esos espacios en que ellas no tienen tiempo para ir a todas las instancias de reflexión que tenemos, donde estas discusiones no les llegan por sus círculos o por sus redes y lo más cercano que tienen es lo que ven a la pasada en la mañana en el matinal mientras se van corriendo a trabajar. Por eso, el saber apoderarse de todos los espacios, incluyendo a los medios, es muy importante. Se ha dado mucho la discusión dentro de las tomas, paros y asambleas, que dice que las feministas no deberían legitimar la prensa burguesa, la prensa sexista, porque el mensaje que se quiere trasmitir es otro. Para mí es conflictivo tener una postura tan tajante sobre esto, porque, por ejemplo, es muy difícil que la señora dueña de casa llegue a la revista hípster feminista que reparten en barrio Lastarria. Es muy difícil llegar si sólo te centras en el nicho privilegiado en el que estamos, y sí, la forma de llegar es a través de los matinales, de diarios más populares. Quizás es el mismo diario que publica la Bomba 4, pero hay casas donde no llega otro tipo de medios de información.

Alejandra Araya: y no llegan las redes sociales.

Araceli Farías: la dueña de casa no usa Instagram. Se planteó en un momento que usáramos Instagram y chao.

Camila Vallejo: las adultas mayores no usan Internet y hay lugares donde no llega Internet.

Araceli Farías: en regiones es peor, donde hay gente de nuestra generación que tiene acceso a internet una vez a la semana. Son cosas de las que no nos estamos 
haciendo cargo y creo que es importante rodearse de esos espacios. También hay que preocuparse de cómo llegamos a las nuevas generaciones, lo que en mis distintos espacios de participación ha sido un tema de discusión. Esta nueva generación millenial, híper sensibilizada, con exceso de la información, que tiende a ser más esquiva con el sentido de responsabilidad, de sacrificio de la militancia, el compromiso con algo colectivo. Es un desafío saber involucrar a las nuevas generaciones para que esto no se termine con los que estamos ahora y que después nadie más sepa seguir llevando este proceso en los distintos espacios.

Claudia Apablaza: bueno, el desafío es complejo, es difícil, porque casi siempre los grandes movimientos son elitistas, son movimientos de personas que tenemos los recursos para poder trabajar ciertas temáticas, pensar ciertas temáticas. Por ejemplo, yo me sentía en la cresta de la ola feminista hace seis meses y de repente a nosotros en la editorial se nos dio un caso de un autor que fue acusado de abuso y nosotros le bajamos el contrato. Lo íbamos a publicar tres meses después y alguien en las redes sociales lo acusó de violación y nosotros decidimos interrumpir el contrato con este chico. Yo tengo una hija de dos años y a veces una señora me ayuda a cuidarla. Yo le conté a ella: "pasó que una chica, gestora cultural, acusó de abuso a este autor y tuvimos que ver todo el tema legal, cómo trabajar con el tema de que ya no lo íbamos a publicar, qué hacíamos con las redes sociales". Ella me pidió que le explicara bien cómo se había dado el abuso. Le conté que, bueno, estaban en un carrete en la playa y esta chica estaba durmiendo, tal vez había bebido, y él se metió a la pieza y abusó de ella. Me dijo: "pero cómo, si uno cuando está curado está caliente". Y yo dije: "oooh, hay que partir de mucho más atrás".

Camila Vallejo: sí, es que uno está pasado siete cuadras más allá y hay que partir siete cuadras antes.

Claudia Apablaza: nosotros, por ejemplo, tenemos un libro que se llama Quiltras, de una autora que se llama Arelis Uribe, y nos iban a comprar una cantidad importante de libros del Ministerio de Educación. Pero de repente nos mandaron un mail y nos dijeron que no lo podían comprar, porque alguien había bajado la compra. ¿Por qué? Es que son temáticas que no se pueden trabajar en los colegios, nos dijeron. Nuevamente me vi enfrentada, ya no sólo a la señora que cuida a mi hija, sino que al Ministerio de Educación, que en el fondo nos baja una compra porque considera que los contenidos no son adecuados. Es complejo el desafío, hay que atacar muchos frentes, desde el educacional al circuito literario. Siempre lo pienso desde ahí: cuando empecé a publicar no me sentí apoyada por las escritoras mayores que yo. Uno de los desafíos que tenemos las mujeres de mi generación es 
apoyar a las nuevas escritoras y mantener un discurso que no se pierda. Al principio de todo era mucha soledad lo que sentíamos las mujeres publicando ciertas líneas ideológicas, creo que uno de los desafíos es tratar de mantener un cierto discurso y acompañar a las chicas que van a publicar de otras generaciones, decir que no todo está perdido. Ese es otro desafío que veo desde la literatura.

Alejandra Araya: bueno, para cerrar hay una cosa relacionada con toda esta riqueza de la discusión política, social, que ustedes están expresando. Al parecer, por lo que ustedes han dicho y lo que uno ha estado escuchando, hay una cierta tensión entre género y feminismo. Una de las razones por las que este feminismo quedó en silencio fue por la institucionalización de la agenda de las mujeres en los gobiernos concertacionistas y porque esa institucionalización fue un poco negativa respecto al potencial más político de la agenda. ¿Cómo se plantean al respecto? Emilia lo dice con más claridad, tienes una postura más crítica de estas agendas de género, y al parecer ahí habría una tensión conceptual y práctica entre las políticas de género y equidad y el feminismo. ¿Es real? ¿Es algo de lo que hay que hacerse cargo?

Camila Vallejo: lo que yo creo que hay es una contradicción y no es tan lineal. No me parece que sólo porque se haya institucionalizado el debate o se haya focalizado en un departamento en el SERNAM, el movimiento no haya tenido expresión. Yo sí creo que uno de los problemas grandes que tuvo la Concertación fue abandonar el movimiento popular y encerrarse en la transición y en los acuerdos con la derecha. Eso es una lectura correcta para todos los ámbitos, creo que es un problema generalizado, pero siento que no es suficiente. Porque está pasando en el mundo entero. Hubo una etapa de silencio, el movimiento feminista ha tenido varias expresiones, hace siglos o en las décadas de los ' 60 y ’ 70 , que fueron bastante radicales. Pero hay algo que yo no sabría explicar de por qué se mantuvo en silencio por tanto tiempo o al menos creo que no es sólo por eso. Porque, además, debates bien insuficientes en esta materia igual permitieron reabrir un debate público. El que tengamos un Ministerio de la Mujer y Equidad de Género, por más insuficiente que sea, también creo que es algo que te permite decir "por qué el Estado no ha sido capaz de avanzar en tantas otras materias". Ese era el debate que estaba puesto sobre la mesa. Hoy la derecha quiere fusionar el desarrollo social y la familia, pero creo que esas pequeñas cosas, aun siendo insuficientes, lograron contribuir a abrir un debate, más todas estas experiencias acumuladas de violencia que empezaron a visibilizarse por las redes sociales.

La izquierda cree que sólo la teoría resuelve los problemas, pasó lo mismo en el movimiento estudiantil y está pasando ahora. No podíamos ir a los programas 
de televisión, no podíamos ir al Congreso porque era venderse a la burguesía, y nosotros decíamos "no, hay que disputar todos esos espacios". Si quieres combatir el sistema tienes que entrar a disputar eso, si no, te quedas aislado. Yo creo que eso ha debilitado la posibilidad de que la mirada más revolucionaria, transformadora, llegue a sectores que son imprescindibles para generar transformaciones profundas. Hay que combinar avance legislativo con disputas del discurso hegemónico de los medios masivos, aunque sean de derecha, conservadores y machistas; entrar ahí y penetrar esos espacios. Lo otro, mostrarle cuestiones concretas a la gente. ¿Qué hace la derecha? La canasta, las redes clientelares llegan al poder y perpetúan su política. ¿Qué es lo que le ofreces concretamente a la gente? Que no sea sólo el discurso de "hay que cambiar la Constitución", por ejemplo. ¿Cómo conectan eso con su estilo de vida? Cómo las mujeres de las poblaciones te van a creer si sólo dices que esto es una transición hacia un sistema distinto porque la teoría según Marx, según Gramsci, según otra teórica feminista dice esto... Esa es la debilidad que hemos tenido, creo yo, haciéndonos la autocrítica desde la izquierda más que sólo cuestionar a los otros.

Vuelvo a retrotraer la situación al movimiento estudiantil. Todos estábamos de acuerdo con que la educación era un derecho y no un privilegio, todos estábamos de acuerdo. Sin embargo, al momento de entrar a concretar ese ideario, la gente ponía resistencia desde los sectores populares porque no querían que sus hijos se mezclaran con los vecinos, querían pagar por la educación justamente para auto segregarse. Y por qué pasó eso, porque no se hizo el trabajo de la pedagogía del tú a tú y entender además las condiciones materiales de la gente y por qué pasa eso, por qué la gente quiere segregarse. Entonces, yo creo que pasa lo mismo con el feminismo y la resistencia que genera muchas veces el movimiento en ciertos sectores, porque para el que ha estado educado desde chico en una lógica machista patriarcal, mujeres y hombres, que lo tienen en su $\mathrm{ADN}$, que es su forma de vida, tratar de deconstruirlo de un día para el otro genera una resistencia muy fuerte.

Alejandra Araya: y más violencia.

Camila Vallejo: y más violencia. Lo mismo para el que está acostumbrado a pagar para que su hijo no se mezclara con el niño más violento. Estoy volviendo al tema de los desafíos, creo que es una debilidad que tenemos y que hay que combatir fuertemente.

Emilia Schneider: a mí me pasa cuando hablabas... y es que esta pregunta se instala, yo creo, en el clivaje de por qué las políticas de género en la Concertación 
tienen tal efecto o no en el movimiento feminista actual y por qué son rechazadas por nuestros actores sociales del feminismo. No es institucionalidad versus autónomas, que era este clivaje que se planteaba en la vuelta a la democracia. Las que se iban a meter en la institucionalidad y en los partidos versus las que iban a mantenerse en la organización.

\section{Camila Vallejo: por eso casi se rompe el CONFECH.}

Emilia Schneider: para mí ese no es el clivaje, porque yo creo que efectivamente el Congreso, distintas carteras, la institucionalidad, son herramientas que pueden estar al servicio de esos intereses sociales excluidos o no. Manifiesto este rechazo, diferenciación, respecto a las agendas de género de la Concertación y respecto a la agenda mujer que presenta Piñera y en general las políticas del SERNAM, por dos cosas. Esta discusión entre institucionales y autónomas es lo que empantana justamente el debate y por el carril paralelo la Concertación toma las banderas del movimiento feminista por más autonomía, emancipación, libertad, y las procesa en términos neoliberales. Justamente el efecto que tiene es la desarticulación del movimiento feminista y la sectorialización, es decir, la educación, el mundo del trabajo, no son cuestiones a analizar desde esa perspectiva sino que tenemos un departamento de mujeres. Yo creo que eso es lo complejo, sustraer el tema de la mujer de esos otros conflictos sociales, como si una fuera mujer y después trabajadora, o mujer y después estudiante, o lesbiana y después trabajadora. Esa segmentación es muy compleja.

Ahí también está la cuestión de fondo, las políticas esencialistas de las agendas de género de la Concertación, de la Nueva Mayoría y hoy de la derecha, que se enfocan en la integración social de la mujer en tanto madre, en tanto víctima y en tanto emprendedora. Y con emprendedora me refiero a este mito de la mujer empoderada, que es madre, cuida la casa, es buena esposa y cuida a los hijos, tiene un trabajo. Esa falsa promesa democrática es lo que hace crisis hoy. A eso me refiero con que el movimiento feminista hoy es expresión de la insuficiencia de todo ese proceso. Justamente por eso el movimiento hoy reabre el debate, por el agotamiento de esa forma de democracia en Chile, por esa forma limitada, por esas falsas promesas de democracia. Ejemplos sobran de esa forma de hacer política en Chile, pasó lo mismo por la demanda de gratuidad, que se procesó de una manera en que terminó siendo una política que entrega más dinero a los empresarios y a la educación privada, que la demanda histórica y propia que levantó el movimiento social. Eso también es lo que sucede con el movimiento feminista en los '90, que viene con mucha fuerza, exigiendo democracia en el país, en la casa y en la cama... ¿en la casa o en la cama? me falló la cita. 
Alejandra Araya: en la calle y en la casa, pero recientemente se agregó en la cama. Emma de Ramón lo puso en el Archivo Histórico Nacional.

Emilia Schneider: bueno, yo creo que eso es lo que pasa, esa articulación y ese tomar las banderas del movimiento social y procesarlas. Es la manera de operar en la política en Chile, es lo que mantiene el neoliberalismo en este país, que genera un profundo malestar, pero toman la bandera de la emancipación de la mujer y la convierten en igualdad de oportunidades, la de demanda por la educación pública la convierten en becas, en voucher. Eso para mí es el clivaje con la agenda de género, que esencializa y procesa, y nos subvierte.

Alejandra Araya: claro, pero esto está en el núcleo de lo que hay que discutir ahora.

Emilia Schneider: claro, y es consecuencia histórica y el desafío a superar, de alguna manera. 